EDUCATION AND SOCIAL CAPITAL

John F. Helliwell

Robert D. Putnam

Working Paper 7121

http:/www.nber.org/papers/w7121

\author{
NATIONAL BUREAU OF ECONOMIC RESEARCH \\ 1050 Massachusetts Avenue \\ Cambridge, MA 02138 \\ May 1999
}

Helliwell acknowledges the support of the Social Sciences and Humanities Research Council of Canada. For research on this and related projects, Putnam would like to thank the Pew Charitable Trusts, the Rockefeller Foundation, the Lilly Endowment, the Norman Foundation, the Carnegie Corporation of New York, and the Bertelesmann Science Foundation. For generous help with the DDB Needham Life Style data, we thank Chris Callahan, Sid Groeneman, Marty Horn, and Doug Hughes. The views expressed herein are those of the authors and do not necessarily reflect the views of the National Bureau of Economic Research.

(C) 1999 by John F. Helliwell and Robert D. Putnam. All rights reserved. Short sections of text, not to exceed two paragraphs, may be quoted without explicit permission provided that full credit, including $\mathbb{C}$ notice, is given to the source. 
Education and Social Capital

John F. Helliwell and Robert D. Putnam

NBER Working Paper No. 7121

May 1999

JEL No. I2, J0, H0

\begin{abstract}
$\underline{\text { ABSTRACT }}$
Education is usually the most important predictor of political and social engagement. Over the last half century, educational levels in the United States have risen sharply, yet levels of political and social participation have not. Norman Nie, Jane Junn, and Kenneth Stehlik-Barry (NJS-B) have offered an elegant resolution to this paradox based on a distinction between the "relative" and "absolute" effects of education, with only relative education having positive effects on participation.

Using a broad range of evidence, including the data used by NJS-B, this paper shows that increases in average education levels improve trust and do not reduce participation levels. The contrast with the NJS-B participation results is found to be due to the definition of the educational environment. We use a changing regional comparison group, theoretically preferable to NJS-B's static national measure. Our results point to a more optimistic conclusion about the consequences of increases in average education levels, while leaving open the puzzle of sluggish participation.
\end{abstract}

John F. Helliwell

University of British Columbia

997-1873 East Mall

Vancouver, BC V6T 1Z1

Canada

and NBER

helliwel@interchange.ubc.ca
Robert D. Putnam

Kennedy School of Government

Harvard University

Cambridge, MA 02138

robert_putnam@harvard.edu 


\section{Education and Social Capital}

Education is one of the most important predictors - usually, in fact, the most important predictor —of many forms of political and social engagement - from voting to chairing a local committee to hosting a dinner party to trusting others. Over the last half century (and more) educational levels in the United States have risen sharply. In 1960 only 41 percent of American adults had graduated from high school; in 199882 percent had. In 1960 only 8 percent of American adults had a college degree; in 199824 percent had. Yet levels of political and social participation have not risen pari passu with this dramatic increase in education, and by some accounts (Putnam 1995a and 1995b) have even fallen. For at least two decades, political scientists have mused about this paradoxical "puzzle" (Brody 1978).

Recently, however, Norman Nie, Jane Junn, and Kenneth Stehlik-Barry (1996, hereafter NJS-B) have offered an elegant and potentially powerful resolution to this paradox, beginning with a crucial distinction between the "relative" and "absolute" effects of education. If more people now have a college degree, they argue, perhaps the sociological significance of the credential has been devalued. Social status is, for example, associated with education, but we would not assume that just because more Americans are educated than ever before, America has a greater volume of social status than ever before. To the extent that education is merely about sorting people, not about adding to their skills and knowledge and civic values, then no puzzle remains to be explained. In fact, NJS-B conclude, participation is affected primarily by relative educational levels, and thus has not been (and should not have been expected to be) rising with aggregate educational levels.

The distinction that NJS-B have introduced represents an important insight: Education has external effects, as well as internal ones. In principle, my behavior can be affected not only by my education, but also by that of others around me. The core issue is whether (holding constant my own education), I am more likely or less likely to participate politically and socially if those around me become more educated. Besides its academic interest, the NJS-B conclusion has practical significance. If the negative effects of average education match or exceed the positive effects of absolute education, then raising educational levels is a pointless or even counter-productive way to increase civic engagement. 
We are indebted to NJS-B for clarifying the central theoretical importance of this issue. We are, however, less persuaded by their operational interpretation of "relative." That is, to what population is my "relative education" relative? How should we measure the "educational environment" of which one's civic competition is comprised? Both spatially and temporally, the operational standard adopted by NJS-B (1996: 119 and $227-233$ ) is puzzling.

Spatially, by using national standards, NJS-B in effect assume that my civic behavior is affected by educational levels in communities on the other side of the continent. Logically, this operationalization means that civic participation in Seattle — voting, group membership, and so on-should tend to fall if educational levels in rural North Carolina rise. Indeed, the operationalization adopted by NJS-B assumes that the effect of education in rural North Carolina on Seattle participation rates is fully as great as the effect of education levels in Seattle itself. In some domains - the job market for astronauts (NJS-B: 174), for example - educational externalities may be undiluted by distance, but whether participation in community affairs is like that is, we believe, worth exploring. So we propose to measure relative education relative to the respondent's census region.'

Temporally, by comparing each respondent's education to the level of education of all Americans who were between 25 and 50 years of age when the respondent reached the age of 25, NSJ-B assume a static, backward-looking metric of educational externalities. In some job markets, this may perhaps be a reasonable assumption, but in civic participation it seems implausible. For example, this operational measure of relative education means that the participation rate of a 55 -year-old is influenced not at all by the educational

${ }^{1}$ Logically, of course, the appropriate standard of comparison might be even more local; indeed, we suspect that it is. Our purpose here, however, is merely to show that even slightly narrowing the spatial standard of comparison (moving from national to regional standards) can substantially affect one's conclusions. A fortiori defining more localized standards of comparison should improve estimates still further, although at some point, an increasingly localized definition might in fact become smaller than the real range of externalities. For example, although we considered using state- or county-level standards in the present analysis, we set that aside out of concern that some externalities might be carried by inter-county or even inter-state commuters. Interregional commuting is vanishingly small. In subsequent work using "relative education," we recommend that sensitivity testing be done to assess the most suitable level of aggregation, but however low that turns out to be, it will, we believe, be smaller than the nation as a whole. 
credentials of her 54-year-old neighbors, but is influenced instead by the educational credentials people long dead. In other words, in NSJ-B's oddly asymmetric world of civic competition, no one ever competes against anyone younger, but everyone always competes against everyone older (including the dead). Here, instead, we propose to compare each respondent's education to all other [living] adults, both older and younger. $^{2}$

In short, while it seems to us well worth investigating whether the civic participation of a Seattle high school drop-out is influenced (positively or negatively) by the educational levels of his neighbors, it seems to us implausible to assume that his participation rate equally or more influenced by the educational level of dead North Carolinians.

One special reason for caution regarding the NSJ-B implementation of their important theoretical insight is (as they fully recognize at p. 134) that since national educational levels have risen monotonically throughout this century, operationally NSJ-B's measure of relative education (defined as it is in national and static terms) is virtually a perfect linear transform of the respondent's year of birth. ${ }^{3}$ Thus, there is the risk that this operational definition of relative education might falsely take credit for many other factors that have also been changing nationwide and affecting generations differently.

In this research note, in sum, we explore whether the important findings reported in NSJ-B regarding the effects of relative education on civic participation are robust when a more finely tuned operational definition of the educational environment is employed.

\section{Are the Effects of Education Relative or Absolute?}

${ }^{2}$ Again, of course, this implementation could be tuned more finely to fit specific models of civic competition. Our claim is merely that it is more plausible than a purely static, backward-looking model.

${ }^{3}$ A close approximation to the NJS-B measure of educational environment, measured in average years of education is provided by edenv $=9.0+.07273 *$ yob $-.03333 *($ yob-55)*d55, where $\mathrm{d} 55$ is a variable that takes the value 1.0 where yob $>55$, and zero elsewhere. The equation is thus piecewise liner with a kink at $y o b=55$. The national average level of education thus rises by .073 for each year of birth up to 1955, and at .04 (=.073-.033) per year for years of birth after 1955, as shown in Table F3 of NJS-B $(1996,232)$ 
The basic theory underlying the NJS-B hypothesis is that education is for many activities a sorting mechanism used to distribute a fixed number of opportunities for gainful participation. Thus more education for an individual makes him or her better able and more likely to compete for a place of influence and activity, while increases in general education have no such effect. They argue that this relative education hypothesis has no claim to universal applicability, and recognize that, at least for some activities and attitudes, increases in average education levels may well have positive effects. They distinguish three main alternatives: a purely relative effect, as described above; an absolute effect, whereby the education effect depends only on an individual's own education and not on the education levels of others; and a cumulative effect, whereby there are positive feedbacks from general education levels to the individual's own actions or attitudes.

They test among these possibilities by defining separate variables for an individual's own education, and for the average level of education in the individual's "educational environment," as defined above. If the positive effects of one's own education are offset by equal and opposite effects from the average education level, then the relative education model dominates. If one's own education has a positive effect, with no significant effect from the average level of education, then the absolute or additive model dominates. Positive effects from both own education and average education would provide evidence favouring the cumulative model, where the effects of education are super-additive, since education has both direct and indirect positive effects. Mixed cases are of course possible.

Their reasoning and empirical results provide them with examples of each type of effect in operation. For political and social engagement they argue that the relative education model should well dominate, because of a relatively fixed amount of total benefits from participation. For cognitive abilities, they find a large positive effect of own education, combined with a relatively small negative feedback from average education levels. ${ }^{4}$ They see the predominance of the own-education effect as reasonable, because education can increase one person's cognitive skills without lowering those of anyone else. This, they argue, is in contrast with political and social participation, where increased participation by one is expected to reduce the gains available to others, because of competition for a fixed pool of benefits. They find, for organizational

${ }^{4}$ The authors argue that the negative effect from average education levels "...represents decreasing marginal returns for additional education rather than indicating increased competition." NJS-B (1996, 162). 
memberships, that each year of own-education has a substantial positive effect, but that this is offset by an even larger negative effect from each year of increase in average education levels. ${ }^{5}$ For tolerance, they find that one's tolerance is increased not only by one's own education but also by the average education level of those in the surrounding community. They find that both own-education and average education have significant positive effects, with the effects of average education being even larger than those for own education. ${ }^{6}$

The theoretical argument in favour of the cumulative or super-additive effects of education can also be made for social trust. Higher average education levels may help to create a climate of trust that is selfreinforcing. If individuals know that higher education levels make others more likely to be trusting (and perhaps also more trustworthy), then they are in turn more likely to trust others. Hence the returns to trusting behaviour are increased where there are increases in average levels of education, so that it should be expected that people of any level of education are in fact more trusting of others in an environment marked by higher average education levels.

Going further, we think that the argument that NJS-B use to support the finding of cumulative or super-additive effects of education on tolerance can be used equally well to support a finding of additive or cumulative effects of education for many types of social interaction, including political and community engagement. When deciding whether we want to participate in clubs or community life, are we not more likely to find such activities personally and socially rewarding if there is a climate of trust and tolerance among those with whom we are working? It is fairly well established that high levels of trust reduce the costs of getting things done, since in the absence of trust it is necessary to have rules and enforcement that provide expensive and cumbersome insurance that the agreed purposes of the organization will be pursued as hoped and expected. This will be true even if the number of leadership positions in such organizations does not increase proportionately with membership, and even if some organizations may have to compete harder for opportunities to make their way if the field becomes more crowded.

\footnotetext{
${ }^{5}$ NJS-B $(1996,163)$.

${ }^{6}$ NJS-B (1996, 148).
} 
Moreover, it is likely that for some types of organization the opportunities for beneficial involvement by individuals may actually increase with the extent of involvement by others. For instance, a reading group is more likely to be of interest if there are other members with educated interests in the same issues. Likewise, participation in a community sports team will be more attractive if there are enough clubs and teams to make up a good schedule of games with comparable teams. Even the leadership point may cut both ways. Some organizations have jobs to do that are widely regarded as important, while individuals would in general prefer that someone else does the work. One example may be provided by home and school organizations. These may not even exist without a sufficiently large and committed group of interested parents, so in this case we might expect that I am actually more likely to participate in such organizations if educational levels around me increase.

But beyond some point one might expect the relative education model to come into play. After some point, any increase in the number of interested and able parents may diminish the need for any particular parent to be involved without thereby threatening the ability of the organization to do its job to general satisfaction. This might lead to a negative effect, after some point, in the effects of average education on participation. This need not reflect increased competition for the number of available positions, but signal instead the favourable effects of a larger pool of available volunteers.

Leadership roles in community organizations may not be prizes for which there is competition, but jobs that are taken by those willing to take their turn or do their share to keep valuable activities moving along. Thus one may be grateful that someone else is able and public-spirited enough to do the organizing of the local sports club, and be more inclined to join if the club has a larger group of potential helpers with whom to share the job of arranging the schedules and teams. This would provide another reason for anticipating that average education levels might have positive rather than negative effects for at least some types of group memberships.

For us, it is thus an open question, in terms of theory, whether education effects should be relative, additive, or super-additive, for different types of trust and participation. We agree with NJS-B that the case for expecting cumulative or super-additive effects may be greater for trust and tolerance than for some types of participation. Thus we think it is important to consider a number of different types of participation, as well 
as to use multiple sources of primary data. Our results, presented in the next section, are much more optimistic than those found by NJS-B, because we find much less evidence of relative education effects. We find large and pervasive positive effects of general education increases on levels of trust and participation. While NJS-B find that increases in average education have no net effect on social engagement (i.e the positive own-effects are offset by negative effects from the rising educational environment), we find that social engagement increases with average levels of education. We will therefore be able to make the more optimistic conclusion that education can be seen as increasing rather than merely redistributing social capital.

\section{Empirical Results}

In this section we present results on the effects of own and average education levels on measures of both trust and participation, using pooled time-series and cross-sectional data from the US General Social Survey (GSS) from 1972 through $1996^{7}$, and from the DDB-Needham Life Style survey data from 1975 through 1997. The advantage of both data sources is that they cover a large enough span of years, with enough individual observations in each year that there is some possibility of disentangling the complex interplay of generational, cohort and individual factors affecting trends in trust and participation. The GSS employs interviews with randomly selected samples, while DDB uses annual written mail questionnaires of a recruited panel of participants. Although the demographic makeup, questions, and survey procedures differ between the two surveys, the trends evident in the two bodies of data are strikingly similar, thus increasing the assurance that conclusions are not a result of specific features of the methods and questions used in a particular survey. The GSS data have also been used by NJS-B and many other researchers, while the DDB data provide a fresh set of observations.

We look first at the effects of education on measures of social trust, and then deal with measures of social engagement. The social trust findings are in Table 1, which shows the results from equations with fully specified controls as well as from stripped-down equations based only on individual and average levels of education, controlling only for a possible time trend. As described above, the measure used for average education differs in two important ways from that used by NJS-B, first by restricting the comparison group to

${ }^{7}$ The GSS participation results cover 1974 through 1994 only, because the membership questions were not asked in the 1972 and 1996 surveys. 
those in the census region in which the respondent lives, and second by permitting the comparison group to change as time progresses. We do this by defining the educational environment as the average education levels of all adult respondents to the same survey in the respondent's census region. As we have noted, an important statistical benefit of making the comparison specific to the census region is that the variable then has more variation among respondents in the same time period, and is therefore more free of contamination from correlation with other national time trends that may influence trust and participation. ${ }^{8}$

The GSS and DDB ask slightly different questions about social trust, and scale their results differently, raising difficulties for exact comparisons. The GSS asks a standard question used in many social science surveys: "Generally speaking, would you say that most people can be trusted, or that you can't be too careful in dealing with people?" The DDB's simpler question asks respondents to record their agreement or disagreement, on a six-point scale, to the statement "Most people are honest". We present two sets of results using the DDB data, one based on the six point scale, converted so that 1.0 represent full agreement and 0 complete disagreement, and the second converted to a binary equivalent, with any form of agreement being given the value 1.0, and any form of disagreement the value of zero. The second form is more directly comparable with the GSS binary coding, which uses the value 1.0 for agreement that most people can be trusted and 0 for agreement with the alternative that you can't be too careful. As might be expected, there are more affirmative answers to the DDB question than to the GSS, since the GSS offers an alternative that many may agree with more strongly than they accept general trustworthiness. 9

The equations in Table 1 show separately the effects of own-education and average education, both measured in years, on the GSS and two DDB measures of social trust. Equations (i) through (iii) show the education effects based on a fully specified model attempting to account for a number of other factors that have been found to influence social trust, while equations (iv) through (vi) present results from a much

${ }^{8}$ The use of a reference group based on the current adult population also has the advantage that the change in the sample average level of own-education from year to year is equal to the corresponding change in the educational environment.

${ }^{9}$ The DDB results are very similar to the results of a 1983 GSS experimental form that offered only the trusting alternative. 
cruder model including only education, average education, and a linear time trend. ${ }^{10}$ Both models show positive effects from both own and average education levels for all three measures of social trust. These positive effects are very large and highly significant in the simple model, and smaller and weaker in the fully specified models, presumably because the larger models contain a number of other variables that share some of the same regional and time series variation as average education. "In the simple models, the effects of average education on trust are about twice as large as those from own-education, echoing the earlier results of NJS-B for tolerance. In the fuller models they are about half as large. Using the GSS results shown in the first equation, each additional year of education increases one's likelihood of being trusting by .044, or just over $10 \%$ of the average likelihood of .38 . A one-year increase in the average level of education in one's region increases one's trust by .024 . Thus increases in average education levels, acting both through owneffects and education levels in the surrounding community, have had strong positive effects on social trust over the past twenty years. With average education increasing by almost 1.5 years from the mid-1970s to the late $1990 \mathrm{~s}$, the implied impact on trust is about .1, an increase equal to almost one-quarter of the average level of trust on the mid-1970s, and almost as large as the entire drop since that time. Thus the effects of changes over time in average education levels double the size of the decline in trust to be explained by other factors.

We turn now to consider the results for participation. First we shall compare the GSS and DDB

10 The nature and estimated effects of the control variables are reported in the Appendix. The coefficients reported are from the linear probability model estimated by OLS. The normality of residuals assumed in OLS regression is false, since the dependent variable falls into the range between 0 and 1 . We used logit estimation of the binary equations to see if non-normality of the residuals is affecting the results. Logit estimation of the equations with binary dependent variables, with coefficients renormalized to be comparable with those from the linear probability model, show no change in the pattern of results. For example, the transformed logit coefficients for education and average education in equation (i) are .050 $(\mathrm{t}=37.1)$ and $.027(\mathrm{t}=3.1)$, and in equation (iv) $.044(\mathrm{t}=34.9)$ and $.067(\mathrm{t}=11.2)$. These are almost identical to those shown in Table 1.

${ }^{11}$ Similarly, the time trend coefficients are larger and much more significant in the simpler model than in the fully specified model. This is as we would hope, as one of the objectives of fuller specification is to expose the underlying reasons for the downward trends in social trust. A fully specified model would leave little or nothing to be explained by time alone, in the absence of some theory suggesting why the passage of time should be sufficient to erode social trust. The simpler model includes the time trend to ensure that any effects found for average education levels are not simply due to the fact that it shares a common time trend with some important excluded variables. 
results for some key forms of participation, and then present the GSS results for sixteen different types of organization. Table 2 shows the education results from both fully specified and simple models for total memberships from the GSS, plus three key types of social engagement as measured by the DDB surveys. These DDB participation measures represent the number of times that the respondent reports participating in each of these activities in the previous year: (1) attend a club meeting, (2) work on a community project, (3) give or attend a dinner party. For three out of four measures of social engagement, own-education has a strongly positive effect, and average education levels, where significant, are positive. The only estimated negative effect of average education levels is for total memberships from the GSS survey. Even there the estimated negative effect of average education levels is small and insignificant. This is in sharp contrast to the NJS-B $(1996,247)$ results for GSS total memberships. They report an own-education effect of +.20 , fairly close to our estimate of +.23 . However, for average education, they find a significant negative effect of -.24 , while our negative effect is only one-tenth as large, and is insignificant. Since the explanation of this difference is a primary aim of this paper, it will be treated separately, in the next section.

The DDB equations provide further and independent confirmation of the general lack of relative education effects, since all of the four types of activity show positive effects from average education levels, two of them with statistical significance. The DDB participation measures are in some ways preferable to the GSS data, since the latter show only the number of types of organization to which the individual belongs, and not the extent of involvement. The DDB data, by contrast, ask for the frequency of involvement in each of the types of activity. The sample size is also much larger for DDB, although in both surveys the range of years covered, and the number of respondents in each year is large enough, that small sample size is not likely to be a problem.

Comparing the results for the GSS and DDB equations is made more complicated by the different form of the questions and coding. The coefficients are generally higher for the DDB responses, but then so are the average values for the participation measures. To get a rough measure of the extent to which the proportionate responses are similar, the coefficients shown in the table should be divided by the sample averages for the dependent variables, as shown at the bottom of Table 2 . With these adjustments made, the effects of own education are quite similar across the types of involvement. A one year increase in education leads to an estimated increase in participation ranging from $9 \%$ for number of dinner parties to $14 \%$ for 
number of involvements in community projects. The effects of average education are more varied, and much less precisely estimated. An increase of one year in the average level of education in one's region increases the number of dinner parties given or attended by $20 \%$, increases the involvement in community projects by $5 \%$, has no effect on club meetings attended, and reduces the number of memberships (the GSS variable) by about $1 \%$.

We turn in Table 3 to consider the effects of education on memberships in the sixteen different types of organization covered by the GSS memberships question. The dependent variable for each of the sixteen equations is equal to the fraction of the respondents who said they were a member of an organization of the type mentioned. The figure for total memberships is the sum of the answers for the sixteen types. Given the linear regressions used, it follows that the coefficients for total memberships are simply the sums of the coefficients on the same variable in each of the sixteen categories. Thus the equations for the different types of membership show where the aggregate effects are coming from.

Inspection of the results for specific groups shows how hard it is to generalize across groups with very different purposes, recruiting methods, advantages to members, and degree of commitment required of members. Own-education effects are positive for all forms of membership except for unions. The proportionate own-education effects are largest, unsurprisingly, for professional organizations, since such organizations generally have advanced education as prerequisites for membership. The negative owneducation effect for union membership follows from similar reasoning, since unionization rates are generally higher on the shop floor than in management positions, while educational qualifications follow a reverse pattern.

Average education effects are generally small and insignificant. Significant positive effects for average education are estimated for literary groups, a finding foreshadowed by our earlier discussion. A book group is more likely to be formed, and to offer a links to other readers with similar interests, where average education levels are higher, and there seems to be no reason to think that the social structure sets any upper limit to the number of book groups. Average education effects are also positive for sports groups, although significantly so only in the simple form of the equation. 
Average education effects are significantly negative only for unions, church groups, and farm organizations in the full equations, and for school groups in the simple equations. The relative education hypothesis does not apply easily to the union and church group cases. For unions, both the own and the average education effects are negative, presumably for the same reason, with lower average education providing the greater critical mass needed for successful working-class organization. For church groups, the negative effect from average education exceeds the positive effect from own education, suggesting that regions (and time periods) with higher average education levels also have lower average ratios of church membership, though we doubt that this is attributable to the social competition emphasized by NJS-B. For farm and school groups, the negative effect of average education may reflect the kind sorting effect emphasized by NJS-B, or perhaps some burden sharing of the sort we have described earlier. Some farm groups may represent professional organizations in which membership is simply part of being in the business, with a negative average education effect reflecting in part differences in average education levels in census regions with different concentrations in agriculture.

\section{Unravelling the Puzzling Contrast}

Why do our results for average education differ so much from those of NJS-B? The differences could be due to estimation method, sample size, choice of control variables, or differences in the definition of average education. We shall show below that the differences are entirely due to differences in the definitions of average education. In any specification using our definition of average education, the NJS-B negative effect of average education disappears. This happens whether we use their control variables, our alternative control variables, or simple equations with no control variables. Although we use the same corrected GSS data for total memberships used by NJS-B, our control variables differ somewhat from theirs, and their sample size is about $15 \%$ smaller. Their smaller sample size (15887 compared to 19214) is due to the unavailability of data for some of their control variables. We have tried to include only control variables that are available for almost the full sample, while testing to see if allowing for other control variables available only for some of the data (e.g. parents' education) makes any difference to the fundamental results. There are some slight differences in the statistical methods used. We include, in the Table 2 equation for GSS memberships, a linear time trend, while NJS-B use a more general method by inserting separate dummy variables for all but one of the individual years. To see if the different method of allowing for year effects has 
any impact on the education results, we have re-estimated equation (i) of Table 2 using year fixed effects instead of a linear time trend. The resulting coefficients for education and average education in the last row of Table 3. As can be seen, the education coefficients are unaffected. If the results did differ, the NJS-B allowance for year fixed effects would be preferred to what we do in Table 2, since it is a more general statistical method. We include both sets of results to show they are identical, and use the linear time trend elsewhere in Tables 1 and 2, since we are interested in showing the extent to which trust and social engagement are changing through time, with and without controlling for other variables.

To provide a more definitive answer to the puzzle, we have drawn a sample of data as close as possible to that used by NJS-B, and then tested average education effects in the context of three different equations: first using their control variables, then using ours, and finally using a simple model containing only education, average education, and fixed effects for each survey year. ${ }^{12}$ We have then estimated these equations using the NJS-B measure of average education, our measure, and two intermediate measures designed to show which of the differences play the most important roles in explaining the puzzle. All these results are shown in Table 4

As noted above, NJS-B define the educational environment as the national average of education years of those who reached the age of 25 in the same year as the respondent, or in any of the 24 preceding years. In our view, this is too broad in being national rather than regional, and too unresponsive to the changing environment, by excluding all those who are younger than the respondent while continuing to include many who are dead and gone. We define average education as the average number of years of education of currently surveyed adults in the same census regions, arguing that this best represents the social environment which the individual is deciding whether to trust and join. Our measure thus uses a changing regional peer group while NJS-B use a static national reference group. The results for education and average education

12 Our replication of the NJS-B equation does not yet provide an exact match, although the results for education and average education are so close to theirs that full replication is not likely to change the pattern of results. We have approximated the NJS-B measure of relative education by modelling it as a piece-wise linear function of year of birth, with a kink at 1955, as shown in Table F-3 of NJS-B (1996, 232). Our current equation includes all of the other variables they use, except that hours worked are not included, since the number of valid observations in the GSS database is several thousand less than the NJS-B sample of 15887. Our current equation has a sample size of 18037. 
based on the NJS-B definition are shown in column (i) of Table 4. To help show the influence of the two differences between our definition and that of NJS-B, we have also defined two mid-way variables, one using a static regional peer group and the other a dynamic national peer group. These results are shown in columns (ii) and (iii) of Table 4, while the results from our variable, which employs a dynamic regional peer group, are shown in column (iv).

The three panels of results, moving from top to bottom in Table 4, make use of the NJS-B control variables, our control variables, and no control variables. All equations include year fixed effects. The first important conclusion from the results is that the negative effect of average education falls sharply moving from left to right in the table, whatever control variables are used in the equation. Looking first at the top panel, using the NJS-B control variables, the negative average education effect falls almost in half using a static regional peer group, and disappears entirely with either a dynamic national or a dynamic regional peer group. Using our control variables, as shown in the middle panel, the negative effect of average education falls by more than half with a static regional peer group, becomes positive with a dynamic national peer group and is insignificantly negative with the dynamic regional peer group. In the simple equation, with no controls, the negative effect of average education remains strong with the static regional peer group. It is still large, but statistically weak, with the dynamic national peer group, and drops to one-third the size of the own-education effect when our dynamic regional measure is used. As may be recalled from Table 3, the negative average education effect in the simple equation for total memberships can be traced to church membership. This explains why the negative average education effect disappears in the fully specified NJS-B equation, but not in the simple equation, since the NJS-B control variables include church attendance with a strong positive coefficient.

Thus we can conclude that in either of the fully specified models the negative effects of average education on GSS memberships disappear when the static national peer group is replaced by a dynamic regional one, with the shift from a static to a dynamic reference group being the most important part of the story.

\section{Conclusion}


We have presented a range of data designed to show the effects of education on trust and social engagement, two key variables often used as measures of social capital. We have paid special attention to the relative education hypothesis of NJS-B, who report evidence suggesting that only relative education is likely to influence political and social engagement. For trust, our results support their findings for tolerance, with increases in own-education and average education both leading to significant increases in social trust.

For several measures of social engagement, our results differ significantly from those of NJS-B, and are much more optimistic about the social benefits of increases in the width and depth of education. We find no systematic evidence that increases in average education have any negative effects on participation, let alone of the size required to offset the large positive effects of own-education. Since we prefer our definition on theoretical grounds in both respects in which it differs from theirs, we are inclined to put more weight on our results. If we are right, then the Brody (1978) puzzle about declining political participation in America remains unresolved.

\section{References}

Richard A. Brody. (1978). "The Puzzle of Political Participation in America," in Anthony King, ed. The New American Political System (Washington: American Enterprise Institute for Public Policy Research)

Nie, Norman H., Jane Junn and Kenneth Stehlik-Barry (1996) Education and Democratic Citizenship in America. (Chicago: University of Chicago Press).

Putnam, Robert D. (1995a) "Bowling Alone: America's Declining Social Capital". Journal of Democracy 6: $65-78$.

Putnam, Robert D. (1995b) "Tuning In, Tuning Out: The Strange Disappearance of Social Capital in America”. PS 28: 664-83. 
Table 1

Comparing GSS and DDB Evidence on Social Trust

$\begin{array}{lllllll}\text { Equation } & \text { (i) } & \text { (ii) } & \text { (iii) } & \text { (iv) } & \text { (v) } & \text { (vi) } \\ & \text { GSS } & \text { DDB } & \text { DDB } & \text { GSS } & \text { DDB } & \text { DDB } \\ \text { Sample } & 1972-96 & 1975-97 & 1975-97 & 1972-96 & 1975-97 & 1975-97 \\ \text { Dependent variable: } & 22445 & 76156 & 76156 & 22445 & 76156 & 76156 \\ & \text { Trust } & \text { Honest } & \text { Honest } & \text { Trust } & \text { Honest } & \text { Honest } \\ \text { (binary) }\end{array}$

Equations with full control variables Simple equations with year effects

$\begin{array}{lllllll}\text { Education in years } & .0439 & .0093 & .0175 & .0391 & .0062 & .0133 \\ & (40.3) & (24.4) & (24.8) & (37.0) & (16.0) & (18.7) \\ & & & & & & \\ \text { Average education } & .0244 & .0057 & .0096 & .0602 & .0130 & .0206 \\ \text { in region (yrs) } & (3.2) & (1.6) & (1.4) & (11.0) & (3.6) & (3.1)\end{array}$


Table 2

GSS and DDB Evidence on Social Engagement

$\begin{array}{lllll}\text { Equation } & \text { (i) } & \text { (ii) } & \text { (iii) } & \text { (iv) } \\ & \text { GSS } & \text { DDB } & \text { DDB } & \text { DDB } \\ & 1974-94 & 1975-97 & 1975-97 & 1975-97 \\ \text { Sample } & 19214 & 71246 & 71246 & 71246 \\ \text { Dependent variable: } & \text { Memnum } & \text { Club meetings } & \text { Community } & \text { Dinner } \\ & & \text { (times/year) } & \text { Projects } & \text { Parties }\end{array}$

A. Results from Full Equations with control variables.

$\begin{array}{lllll}\text { Education in years } & .2283 & .7141 & .3504 & .4808 \\ & (51.7) & (36.1) & (33.5) & (41.5) \\ & & & & .9600 \\ \text { Average education } & -.0201 & .0057 & .1710 & (8.7)\end{array}$

B. Results from Simple Equations including only education variables and a time trend.

$\begin{array}{lllll}\text { Education in years } & .2286 & .6167 & .3273 & .4313 \\ & (51.8) & (31.4) & (31.6) & (37.4) \\ \text { Average education } & -.0362 & .0979 & .1344 & 1.227 \\ \text { in region (years) } & (1.1) & (0.5) & (1.4) & (11.4) \\ \text { Mean of dep variable } & 1.78 & 7.46 & & 5.32\end{array}$


Table 3

Effects of Absolute and Relative Education on Types of Membership

Full Equation

\begin{tabular}{|c|c|c|c|c|c|c|}
\hline Column & (i) & (ii) & (iii) & (iv) & (v) & (vi) \\
\hline & Educ & Aved & P-value & Educ & Aved & P-value \\
\hline Membership & ype & & & & & \\
\hline Fraternal & .0155 & .0003 & .0002 & .0110 & .0017 & .0003 \\
\hline & $(21.6)$ & $(0.7)$ & & $(15.7)$ & $(0.5)$ & \\
\hline Service & .0187 & -.0031 & .0026 & .0170 & -.0066 & .0026 \\
\hline & $(25.5)$ & $(0.6)$ & & $(24.3)$ & $(1.9)$ & \\
\hline Veterans & .0034 & -.0054 & .6407 & .0004 & -.0057 & .0799 \\
\hline & $(5.3)$ & $(1.2)$ & & $(0.6)$ & $(1.8)$ & \\
\hline Political & .0092 & .0006 & .0000 & .0079 & .0028 & .0000 \\
\hline & $(18.9)$ & $(0.2)$ & & $(17.1)$ & $(1.2)$ & \\
\hline Union & -.0054 & -.0217 & .0000 & -.0031 & .0337 & .0000 \\
\hline & $(6.4)$ & $(3.6)$ & & $(3.7)$ & $(8.1)$ & \\
\hline Sport & .0171 & .0128 & .0000 & .0230 & .0179 & .0000 \\
\hline & $(17.6)$ & $(1.8)$ & & $(24.5)$ & $(3.8)$ & \\
\hline Youth & .0093 & .0075 & .0017 & .0127 & -.0009 & .0010 \\
\hline & $(12.3)$ & $(1.4)$ & & $(17.5)$ & $(0.2)$ & \\
\hline School & .0178 & -.0021 & .0083 & .0218 & -.0196 & .5825 \\
\hline & $(21.1)$ & $(0.3)$ & & $(26.7)$ & $(4.8)$ & \\
\hline Hobby & .0113 & .0014 & .0137 & .0105 & -.0056 & .1533 \\
\hline & $(15.5)$ & $(0.3)$ & & $(15.2)$ & $(1.6)$ & \\
\hline Greek & .0174 & -.0052 & .0009 & .0166 & -.0125 & .0957 \\
\hline & $(33.3)$ & $(1.4)$ & & $(35.5)$ & $(5.0)$ & \\
\hline National & .0059 & .0044 & .0013 & .0051 & .0047 & .0000 \\
\hline & $(13.1)$ & $(1.3)$ & & (11.9) & $(2.2)$ & \\
\hline Farm & .0018 & -.0081 & .0719 & .0011 & -.0097 & .0002 \\
\hline & $(3.8)$ & $(2.3)$ & & $(2.3)$ & $(4.1)$ & \\
\hline Literary & .0217 & .0154 & .0000 & .0195 & .0094 & .0000 \\
\hline & (31.6) & $(3.2)$ & & $(29.8)$ & $(2.8)$ & \\
\hline Professional & .0515 & .0070 & .0000 & .0500 & -.0078 & .0000 \\
\hline & $(65.3)$ & $(1.2)$ & & $(66.7)$ & $(2.1)$ & \\
\hline Church & .0233 & -.0415 & .0278 & .0155 & -.0844 & .0000 \\
\hline & $(20.1)$ & $(5.0)$ & & $(13.6)$ & $(14.8)$ & \\
\hline Other & .0100 & .0013 & .0300 & .0075 & .0111 & .0000 \\
\hline & $(13.5)$ & $(0.3)$ & & $(10.7)$ & $(3.1)$ & \\
\hline Memnum & .2286 & -.0362 & .0000 & .2165 & -.0716 & .0003 \\
\hline Total & $(51.8)$ & $(1.1)$ & & $(51.1)$ & $(3.3)$ & \\
\hline
\end{tabular}

Notes: The full equations (i) to (iii) include the same independent variables as the equations shown in Table 2 , except that the variable for year is excluded, and fixed effects are added for each year. The simple equations (iv) to (vi) include only education and average education, plus fixed effects for each year. 
Table 4

Total GSS Memberships with Differing Measures of Average Education

\section{Measures of Average Education}

(1)

Static peer group National average (NJS-B measure) (ii)

Static peer group

Regional average (iii) Dynamic peer group Dynamic peers National average (iv) Regional average (Our measure)

\section{Using the NJS-B control variables}

Education

.2058

(37.6)

Average education

$-.2001$

(8.6)
.2068

(37.5)

$-.1188$

(6.6)
.2007

(36.8)

.0174

$(0.2)$
.2006

(36.5)

.0021

$(0.1)$

Using the Helliwell and

Putnam control variables

Education

.2333

Average education

$-.2648$

(2.3)
.2343

(45.7)

$-.0941$

(2.5)
.2323

(45.7)

.4699

(2.6)
.2335

$-.0478$

(1.3)

Simple equation with year effects but no other controls

Education

Average education
.2404

(48.0)

(16.2)

.2446

(48.1)

(16.4)
.2216

(45.1)

$-.1949$

$-.0826$

(1.8) 


\section{Appendix}

Although the focus of this paper is on the effects of education and the educational environment, it may be helpful to provide some of explanation of the control variables used in the fuller models for trust and participation. The control variables used by NJS-B for their membership equation are fully described by them, and the coefficients reported in NJS-B $(1996,247)$. The variables and coefficients from our alternative control variables are shown in Tables A1 and A2. The following paragraphs explain the variables and their effects on trust and participation.

The TV generation variable is a measure of the likely exposure to television during an individual's formative years, designed to enable a specific test of the negative link between television and social capital put forward in Putnam (1995b). For each individual, the value taken by the variable is equal to the fraction of a person's pre-adult years (from birth to twenty) during which they were potentially exposed to television, weighted by a measure of the availability of television derived from data showing the increases in U.S. television ownership from almost zero in 1950 to over $90 \%$ in 1959. The TV generation variable takes a value of 1.0 for all those born since the late 1950s, and zero for all those born before 1930, with intermediate values for those born in the intervening period. The GSS results suggest that someone brought up before television has a trust level that is higher by .07 , or almost $20 \%$, compared to someone exposed to television throughout his or her formative years.

The TV era variable is the average value of the TV generation variable for all other current respondents in the same census region. It thus relates to the individual TV generation variable exactly as the average education variable relates to the individual measure of education. Exposure to television, like completed education, may have relative, additive or super-additive effects. The results for trust provide some evidence of super-additive effects, with the explanation presumably being the same as for education. If watching television makes individuals less trusting, then it is less rational to be trusting in an environment where many others have also been subject to the same influences. Whether this is in fact the appropriate explanation for the correlation between the TV-related variables and social trust is an issue that we leave aside here, since our primary purpose now is to explore the effects of relative and absolute education. 
Lifecycle is a variable equal to the absolute value of the difference between one's age and 40 . It is intended to capture a possible cohort effect in memberships, with presumed increases in participation up to the age of forty and decreases thereafter. It is to be interpreted jointly with the age effect, as the two coefficients together determine the relative sizes of the participation changes before and after the age of 40 . It is included in the equation to ensure that the TV generation variable is not taking credit or blame for the combination of a cohort effect and a population bulge working its way through the demographic structure. The lifecycle and age variables combine to provide a two-part age effect, with separate slopes, and possibly separate signs, before and after the age of forty. In the GSS equation for trust, the coefficient on lifecycle is negative and much larger than the positive coefficient on age. Putting the two together implies that trust rises with each year of age (by $.0283+.0037=.0320$ ) until the age of 40 , and then falls with each year of age thereafter (by $.0283-.0037=.0245$ ).

The year variable is the year during which the survey took place. A negative coefficient implies that trust was falling through time after accounting for any effects of changing demographic structure, education and any other included variables, such as the extent of likely exposure to television. As already noted, it takes a significant negative coefficient in all the trust equations, with larger and more significant effects in the simpler equations.

The variable male takes the value 1.0 if the respondent is male, and zero otherwise. The GSS results suggest that males are significantly more trusting than females, while the DDB results show the reverse. How can this discrepancy be explained? Fortunately, there is additional evidence that helps to unravel this puzzle. In 1983 the GSS sample was split in two, with half asked the usual question, and the other half asked the simpler question "Generally, would you say that most people can be trusted?" Both males and females were more likely to answer yes to the simpler question, but the difference was far greater for females than for males. The difference in effect is so great that females are significantly more trusting than males if asked the simpler question, but significantly less so when asked the question with the alternative "You can't be too careful". The implication would appear to be that females are more cautious than males, but are also more inclined to think others to be trustworthy. Thus it would appear that the difference in gender effects between the GSS and DDB surveys is sufficiently explained by the difference between the forms of the question, without settling the question of whether there are gender differences in the relative prevalence of honesty and 
trustworthiness.

The variable divorced takes the value of 1.0 for every respondent reporting their marital status as divorced. The results show that divorced persons, in either the GSS or DDB results, are significantly less trusting. An alternative family status variable, used by NJS-B, takes the value of 1.0 for persons so describing their marital status. The two variables give very similar results, with a slight empirical preference for the married version. This suggests that single and widowed individuals have trust levels that are closer to those of divorced persons than of those who are currently married, a presumption that is supported by more specific tests. The choice of which variable to use for family status has no effect on the estimates of the effects of education. The same is true for various variables reflecting ethnic differences in trust and participation.

There are two regional dummy variables in the equation. West North Central takes the value 1.0 for all respondents in the WNC census region. The variable south takes the value of 1.0 for all respondents in the South Atlantic, East South Central and West South Central census regions. Trust levels are higher in the WNC region, and lower in the south, than elsewhere in the country, even after allowing for differences in education, demography and exposure to television. These are the only regional effects that were found to be systematically present in the trust and membership data, with south being important only for trust and for some individual membership categories, but not for total memberships.

The previous discussion has related mainly to the GSS results. The pattern of the DDB results is very similar, except for the sharp gender difference already analysed. Comparing the size of the effects is made more difficult by the differences in the form of the two questions and the gradation of the answers. The DDB trust variable is explained in two ways, once coded as a fraction, and again converted to a binary form similar to that used for the GSS question. The fractional version gives a more precise equation, suggesting that the shades of agreement or disagreement are explained by the same variables used in explaining the binary choice, and that information is suppressed in the binary coding. Comparing the binary form of the DDB equation with the GSS equation, the unexplained variance is very similar (about .46 in both cases), while the explained variance is almost twice as high for the GSS equation. The implication of this is that there is more variance of the explanatory variables among the GSS than among the DDB respondents. This would be the 
case if, for example, the techniques used to select the DDB sample had the effect of producing more homogeneity than is found in the GSS sample or in the population as a whole. This appears to be so, as the DDB sample has fewer divorced persons, and less variance in its distribution of both age and education. Thus the GSS sample has more variance in its dependent variable, and in its key independent variables. This explains why the explained variance is higher for the GSS sample. The fact that the unexplained variance is the same suggests that whatever is missing from the model is found equally among the GSS and DDB samples.

Turning to the participation results in Table A2, we see that the control variables tend to have significant effects, of the same sign, for all four measures of social involvement. The negative effects of TV exposure on participation, which are strong for the GSS membership variable, are less strong for the DDB measures of participation. The negative effects of average exposure to TV are fairly similar across the categories, and larger than the estimated effects of individual exposure. Males are more involved in some types of GSS memberships, but are significantly less intensively involved in any of the three DDB measures of social engagement. Participation is greater in the WNC census region (except for dinner parties) and lower in the south (except for involvement in community projects). 
Table A1

\section{Comparing GSS and DDB Evidence on Social Trust}

Full results including control variables

\begin{tabular}{|c|c|c|c|c|c|c|}
\hline Equation & (i) & (ii) & (iii) & (iv) & (v) & (vi) \\
\hline & GSS & DDB & DDB & GSS & DDB & DDB \\
\hline & $1972-96$ & $1975-97$ & $1975-97$ & $1972-96$ & $1975-97$ & $1975-97$ \\
\hline Sample & 22445 & 76156 & 76156 & 22445 & 76156 & 76156 \\
\hline Dependent variable: & Trust & Honest & $\begin{array}{l}\text { Honest } \\
\text { (binary) }\end{array}$ & Trust & Honest & $\begin{array}{l}\text { Honest } \\
\text { (binary) }\end{array}$ \\
\hline Education in years & $\begin{array}{l}.0439 \\
(40.3)\end{array}$ & $\begin{array}{l}.0093 \\
(24.4)\end{array}$ & $\begin{array}{l}.0175 \\
(24.8)\end{array}$ & $\begin{array}{l}.0391 \\
(37.0)\end{array}$ & $\begin{array}{l}.0062 \\
(16.0)\end{array}$ & $\begin{array}{l}.0133 \\
(18.7)\end{array}$ \\
\hline $\begin{array}{l}\text { Average education } \\
\text { in region (yrs) }\end{array}$ & $\begin{array}{l}.0244 \\
(3.2)\end{array}$ & $\begin{array}{l}.0057 \\
(1.6)\end{array}$ & $\begin{array}{l}.0096 \\
(1.4)\end{array}$ & $\begin{array}{l}.0602 \\
(11.0)\end{array}$ & $\begin{array}{l}.0130 \\
(3.6)\end{array}$ & $\begin{array}{l}.0206 \\
(3.1)\end{array}$ \\
\hline TV generation & $\begin{array}{l}-.0700 \\
(3.3)\end{array}$ & $\begin{array}{l}-.0168 \\
(2.6)\end{array}$ & $\begin{array}{l}-.0403 \\
(3.4)\end{array}$ & & & \\
\hline $\begin{array}{l}\text { TV era (average } \\
\text { of TVgen in region) }\end{array}$ & $\begin{array}{l}-.0583 \\
(0.7)\end{array}$ & $\begin{array}{l}-.0646 \\
(2.1)\end{array}$ & $\begin{array}{l}-.0514 \\
(0.9)\end{array}$ & & & \\
\hline Lifecycle & $\begin{array}{l}-.0282 \\
(6.5)\end{array}$ & $\begin{array}{l}-.00098 \\
(7.1)\end{array}$ & $\begin{array}{l}-.0022 \\
(8.9)\end{array}$ & & & \\
\hline Age & $\begin{array}{l}.0037 \\
(6.8)\end{array}$ & $\begin{array}{l}.00398 \\
(21.4)\end{array}$ & $\begin{array}{l}.00576 \\
(16.7)\end{array}$ & & & \\
\hline Year & $\begin{array}{l}-.0071 \\
(4.4)\end{array}$ & $\begin{array}{l}-.0033 \\
(5.2)\end{array}$ & $\begin{array}{l}-.0054 \\
(4.6)\end{array}$ & $\begin{array}{l}-.0120 \\
(20.8)\end{array}$ & $\begin{array}{l}-.0048 \\
(22.0)\end{array}$ & $\begin{array}{l}-.0073 \\
(18.1)\end{array}$ \\
\hline Divorced & $\begin{array}{l}-.061 \\
(5.0)\end{array}$ & $\begin{array}{l}-.0415 \\
(10.9)\end{array}$ & $\begin{array}{l}-0683 \\
(9.7)\end{array}$ & & & \\
\hline WNC Region & $\begin{array}{l}.102 \\
(8.4)\end{array}$ & $\begin{array}{l}.020 \\
(6.0)\end{array}$ & $\begin{array}{l}.0358 \\
(5.6)\end{array}$ & & & \\
\hline South & $\begin{array}{l}-.051 \\
(6.4)\end{array}$ & $\begin{array}{l}-.0209 \\
(10.3)\end{array}$ & $\begin{array}{l}-.0358 \\
(9.5)\end{array}$ & & & \\
\hline Male & $\begin{array}{l}.033 \\
(5.4)\end{array}$ & $\begin{array}{l}-.013 \\
(7.1)\end{array}$ & $\begin{array}{l}-.025 \\
(7.4)\end{array}$ & & & \\
\hline $\begin{array}{l}\mathrm{R}^{2} \\
\mathrm{SEE}\end{array}$ & $\begin{array}{l}.1074 \\
.466\end{array}$ & $\begin{array}{l}.0758 \\
.248\end{array}$ & $\begin{array}{l}.0517 \\
.460\end{array}$ & $\begin{array}{l}.0754 \\
.475\end{array}$ & $\begin{array}{l}.0135 \\
.256\end{array}$ & $\begin{array}{l}.0110 \\
.470\end{array}$ \\
\hline
\end{tabular}


Table A2

GSS and DDB Evidence on Social Engagement

Equation

(i)

Full results including control variables

\begin{tabular}{|c|c|c|c|c|}
\hline & GSS & DDB & DDB & $\mathrm{DDB}$ \\
\hline & $1974-94$ & $1975-97$ & $1975-97$ & $1975-97$ \\
\hline Sample & 19214 & 71246 & 71246 & 71246 \\
\hline Dependent variable: & Memnum & $\begin{array}{l}\text { Club meets } \\
\text { (times/yr) }\end{array}$ & $\begin{array}{l}\text { Comm } \\
\text { Projects }\end{array}$ & $\begin{array}{l}\text { Dinner } \\
\text { Parties }\end{array}$ \\
\hline Education in years & $\begin{array}{l}.2283 \\
(51.7)\end{array}$ & $\begin{array}{l}.7141 \\
(36.1)\end{array}$ & $\begin{array}{l}.3504 \\
(33.5)\end{array}$ & $\begin{array}{l}.4808 \\
(41.5)\end{array}$ \\
\hline $\begin{array}{l}\text { Average education } \\
\text { in region (yrs) }\end{array}$ & $\begin{array}{l}-.0201 \\
(0.7)\end{array}$ & $\begin{array}{l}.0057 \\
(0.1)\end{array}$ & $\begin{array}{l}.1710 \\
(1.7)\end{array}$ & $\begin{array}{l}.9600 \\
(8.7)\end{array}$ \\
\hline TV generation & $\begin{array}{l}-.5646 \\
(6.1)\end{array}$ & $\begin{array}{l}-.3000 \\
(0.9)\end{array}$ & $\begin{array}{l}-.3243 \\
(1.8)\end{array}$ & $\begin{array}{l}-.5206 \\
(2.7)\end{array}$ \\
\hline $\begin{array}{l}\text { TV era (average } \\
\text { of TVgen in region) }\end{array}$ & $\begin{array}{l}-1.067 \\
(3.2)\end{array}$ & $\begin{array}{l}-2.988 \\
(2.0)\end{array}$ & $\begin{array}{l}-1.565 \\
(2.0)\end{array}$ & $\begin{array}{l}-1.768 \\
(2.0)\end{array}$ \\
\hline Lifecycle & $\begin{array}{l}-.0085 \\
(4.4)\end{array}$ & $\begin{array}{l}-.0475 \\
(6.7)\end{array}$ & $\begin{array}{l}-.0289 \\
(7.7)\end{array}$ & $\begin{array}{l}.0153 \\
(3.7)\end{array}$ \\
\hline Age & $\begin{array}{l}.0031 \\
(1.2)\end{array}$ & $\begin{array}{l}.1404 \\
(14.5)\end{array}$ & $\begin{array}{l}.0422 \\
(8.2)\end{array}$ & $\begin{array}{l}.0305 \\
(5.4)\end{array}$ \\
\hline Year & $\begin{array}{l}-.0138 \\
(2.1)\end{array}$ & $\begin{array}{l}-.2311 \\
(7.4)\end{array}$ & $\begin{array}{l}-.0428 \\
(2.6)\end{array}$ & $\begin{array}{l}-.1746 \\
(9.5)\end{array}$ \\
\hline Divorced & $\begin{array}{l}-.2434 \\
(4.8)\end{array}$ & $\begin{array}{l}-.7877 \\
(4.0)\end{array}$ & $\begin{array}{l}-.3816 \\
(3.7)\end{array}$ & $\begin{array}{l}-1.039 \\
(9.0)\end{array}$ \\
\hline WNC Region & $\begin{array}{l}.290 \\
(5.8)\end{array}$ & $\begin{array}{l}1.106 \\
(6.2)\end{array}$ & $\begin{array}{l}.361 \\
(3.8)\end{array}$ & $\begin{array}{l}-.077 \\
(0.7)\end{array}$ \\
\hline South & $\begin{array}{l}-.034 \\
(0.9)\end{array}$ & $\begin{array}{l}-.531 \\
(5.0)\end{array}$ & $\begin{array}{l}.080 \\
(1.4)\end{array}$ & $\begin{array}{l}-.755 \\
(12.2)\end{array}$ \\
\hline Male & $\begin{array}{l}.238 \\
(9.4)\end{array}$ & $\begin{array}{l}-1.934 \\
(20.5)\end{array}$ & $\begin{array}{l}-.508 \\
(10.2)\end{array}$ & $\begin{array}{l}-1.051 \\
(19.0)\end{array}$ \\
\hline $\mathrm{R}^{2}$ & .1469 & 0594 & .0265 & .0576 \\
\hline
\end{tabular}

